\title{
Discussões Curriculares no Ensino e suas Relações entre Ciência/Tecnologia/Sociedade e História da Ciência
}

Curricular discussions on education and its relations between Science / Technology / Society and History of Science

\author{
M. E. M. Santos ${ }^{1 *}$; N. A. Reis ${ }^{1}$; E. L. Silva ${ }^{2}$ \\ ${ }^{1}$ Programa de Pós-graduação em Ensino de Ciências e Matemática (PPGECIMA),Universidade Federal de Sergipe, \\ Campus José Aloísio de Campos, 49100-000, São Cristovão-SE, Brasil. \\ ${ }^{2}$ Departamento de Química do Campus Itabaiana (DQCI), Universidade Federal de Sergipe, Campus Prof. Alberto \\ Carvalho, 49500-000, Itabaiana-SE, Brasil.
}

*elane.ufsquimica@gmail.com

(Recebido em 13 de outubro de 2015; aceito em 22 de junho de 2016)

\begin{abstract}
O presente trabalho busca apresentar uma discussão sobre currículo escolar, argumentando acerca de alguns aspectos que norteiam o tema no âmbito do ensino de ciências, apontando características do currículo escolar vigente na escola básica e em contrapartida, debatendo tendências a fim de compor um currículo crítico. Defende-se um currículo, considerando às interações CTS, atreladas à História da Ciência, de modo que a inserção da História da Ciência e das relações CTS possa contribuir para o desenvolvimento de atitudes e valores, isto é, de posição crítica diante de problemas sociais. Um currículo crítico deve ir além de visões não equivocadas de ciência e de ensinar ciência, no qual seja possível um aprimoramento de capacidades além do ensino, englobando o social, e, nesse caso, o professor deve atuar em um processo de mediação docente e transformador do pensamento. A elaboração dessas atividades permite argumentar sobre a possibilidade do uso da História da Ciência e do movimento CTS frente ao ensino desfragmentado e disciplinar, portanto, é imprescindível intensificar discussões curriculares críticas já nos cursos superiores, para que assim, tais tendências sejam incorporadas ao cotidiano escolar.

Palavras-chave: currículo, CTS, história da ciência.
\end{abstract}

This study aims to present a discussion on school curriculum, arguing about some conceptual aspects that guide the subject in the teaching of science, pointing out features of the current curriculum and, on the other hand, debating alternatives to compose a critical curriculum. It is argued a resume, considering the CTS relations in order to allow a better understanding on the nature of science. A critical curriculum should go beyond non-mistaken views of science and science teaching, and if it was so, teacher should act in a teaching mediation process. We have just concluded that it is essential to intensify criticism curricular discussions, already in higher education, so that such trends are incorporated into school routine, besides the need for a focused curriculum on CTS relations, and involving historical knowledge aspects.

Keywords: curriclum, CTS, science history

\section{INTRODUÇÃO}

O currículo abrange as políticas que regem as atividades escolares e educacionais, bem como as relações entre ensino e aprendizagem. Essas características compõem uma intencionalidade na prática de ensinar, pois definem atividades que propiciam uma maneira de o aluno chegar a um conhecimento a partir da aquisição de experiências ao longo de um processo de vinculação com a prática pedagógica, visando o aprendizado. As intenções do currículo podem ser diversas e o espaço educacional está em constantes mudanças, no qual se faz necessário que o professor e a comunidade escolar se adequem ao meio, na busca de uma educação de qualidade.

$\mathrm{Na}$ busca de discutir sobre o currículo intencional, o presente texto procura argumentar sobre a problemática do tema no ensino de ciências, procurando apresentar seus encaminhamentos, perspectivas, sua prática e, simultaneamente, as implicações e possibilidades que contribuem para um currículo crítico. E, nesse sentido, debater sobre a intenção de ensinar, a partir de dois eixos contribuintes: as discussões do movimento Ciência-Tecnologia-Sociedade (CTS) e a História da Ciência (HC) para ensinar ciências. De imediato, pode-se inferir que o currículo com inserção 
dessas tendências contribui mais na formação social dos estudantes, comparado às intenções do modelo de currículo tradicional, sendo o primeiro mais significativo para a sociedade e o meio educacional.

Defende-se que o currículo, de maneira particular, um currículo com bases CTS, é um importante meio para uma re(elaboração) escolar, pois auxilia para a construção do papel social da escola, que é formar cidadãos críticos, dirigidas a desenvolver capacidades nos alunos para compreender seu espaço cultural e, ao mesmo tempo, tendo a intenção de transformar seu meio. Desse modo, procura-se responder a alguns questionamentos que surgem no tocante às intenções do ensino, como área específica, o ensino de ciências, articulando as perguntas a algumas propostas entre as relações possíveis entre CTS e História da Ciência.

\section{MATERIAL E MÉTODOS}

Para este estudo, a metodologia utilizada possui caráter bibliográfico e descritivo, pois a discussão está baseada em trabalhos que problematizam discussões curriculares.

\section{RESULTADOS E DISCUSSÃO}

\section{Discussões curriculares e o ensino de ciências}

Com relação ao ensino de ciências, há uma espécie de consenso, quando se fala nos problemas presentes no currículo escolar vigente, tais como currículo tradicional, hegemônico, por competências, entre outros, que são amplamente conhecidos e criticados aos olhos de muitos. Nesse âmbito, a educação constitui-se como um ato intencional, pois há diversos interesses no ensino, e o currículo é alvo principal desse processo de interpretação. Contudo, as discussões sobre currículo escolar envolvem reflexões sobre as relações de poder firmadas pelas políticas e apontam que ainda existem diversos princípios a serem implementados.

O currículo é intencional, planejado e estruturado, mas sua definição não é unânime para o termo. Sendo assim, existem inúmeros conceitos para designar a expressão. Entretanto, o currículo é normalmente definido como um conjunto de atividades direcionadas à educação, ou, como destaca Moreira e Candau [1], como uma visão equivocada, baseada em um conjunto de conteúdo a ser transmitido aos alunos. Em outro entendimento, mais coerente destacado pelos mesmos autores [1], é compreendido como uma construção de conhecimentos selecionados a partir de contextos reais que se configuram pelas distintas instâncias sociais, culturais e políticas. E também, como um instrumento que busca atingir os objetivos do ensino. Na visão de Fávero [2], o currículo é um texto e está relacionado com toda escrita que interage com a prática pedagógica. Entender o currículo implica refletir nas dimensões e forças que o norteia, o que não é uma tarefa simples.

O currículo também é pautado em hegemonias, sendo resultado de disputas de poder que buscam construir um mundo a partir de ideias universais; hegemonias essas, que se originam dos embates que ocorrem nas distintas esferas que permeiam o campo educacional. A escola é permeada por concepções tecnicistas baseadas em um currículo hegemônico que tem buscado unificar os saberes e que acaba por valorizar determinado conhecimento em função dos outros. Tendo em vista isso, Lopes [3] sinaliza acerca de uma necessária mudança nas políticas de currículo que seja contrária a essa hegemonia, mudanças estas que, de acordo com a autora, vai além do apoio financeiro uma vez que há frequentemente a concepção que os problemas na educação estão restritos a questões financeiras. Discutindo sobre as políticas curriculares que estão em vigor, a autora procura compreender as transformações sociais e políticas que norteiam o currículo, com a finalidade de fazer uma nova interpretação sobre o ensino vigente. Entende-se que assim como o currículo, o ensino também é intencional e está permeado por intenções políticas e históricas, principalmente quando remete à seleção cultural dos conhecimentos [4].

Como características dos currículos hegemônicos, a escolha dos conteúdos ocorre com o envolvimento de uma diversidade de forças que atuam sobre o campo educativo. Forças essas que 
são normalmente decorrentes de um Estado Central, agências de fomento, produtores de livros, algo que Lopes e Macedo [4] destacam como "comunidades epistêmicas". Logo, é importante perceber a ideologia dos protagonistas envolvidos na seleção dos textos e conteúdos curriculares, a fim de compreender as ideias sobre as intenções educativas desses. Apesar disso, mesmo o currículo sendo orientado por uma tendência universal de organização, cada contexto possui determinadas peculiaridades locais que também interferem na prática de ensino e na promoção da aprendizagem, ou ao menos, deveriam nortear algumas das finalidades dessas políticas.

O currículo pensado com base na escola e com enfoque na aprendizagem aparece de forma enfática nos estudos de Silva [5], Lopes e Macedo [4], Gouw, Mota e Bizzo [6]. Esses autores apontam que o currículo escolar deve permear o interesse dos alunos, sua diversidade social e contribuir para a formação de pessoas autônomas, que sejam comprometidas com sua realidade social. Sendo assim, a visão de mundo dos estudantes deveria influenciar na elaboração do currículo, a fim de contemplar suas necessidades educacionais e construir um currículo mais significativo, também considerando as necessidades sociais.

Com relação ao currículo escolar para o ensino de ciências na educação básica, algumas ideias conduzem ao tema e procuram refletir a indagações relevantes para a melhoria do ensino, tais como: Que tipo de pessoas se pretende formar? Qual o objetivo do currículo escolar vigente? Quais conhecimentos são indispensáveis para a formação docente? E quais conhecimentos os professores utilizam quando elaboram materiais didáticos para seus alunos da educação básica?

As perguntas descritas remetem a algumas discussões anteriores sobre uma fala recorrente na atual condição educacional, que busca formar pessoas intelectualmente autônomas. Nessa perspectiva, algumas necessidades fazem parte da ação de ensinar, como planejamento de atividades, habilidades interativo-comunicativas, entre outras. A resposta a todas as perguntas levantadas requer uma visão rica e complexa sobre as questões que envolvem essa problemática, principalmente quando se trata da atividade docente [7].

Ainda assim, uma análise detida em alguns dos trabalhos de Lopes [3, 4, 10,13] e outros autores $[1,5,6,8]$, fornecem subsídios para responder parte desses questionamentos. Em um dos seus vários materiais sobre o tema, Lopes [4] infere acerca da centralidade do currículo nas escolas e na formação docente. E assim, destaca que nenhuma instituição de ensino pode ter sucesso se não inserir o currículo como atividade central de organização.

No sentido de buscar respostas mais pontuais para os problemas apresentados acima e com relação ao tipo de pessoas que se pretende formar, Moreira [8] comenta que é necessário considerar o currículo formal e o currículo oculto da escola, ou seja, os conteúdos curriculares e suas relações sociais, pois a interlocução destes dois faz com que haja uma maior contribuição para a formação de pessoas e profissionais. De acordo com Gouw, Mota e Bizzo [6], o objetivo de um currículo escolar não deve ser simplesmente o de estar voltado para o êxito dos estudantes em um exame final, mas deve permitir a eles uma aprendizagem relevante das ciências para suas vidas e para as discussões da sociedade. Afinal, como afirma Chassot [9], o ensino de ciências deve ser voltado para facilitar a linguagem da compreensão de mundo pelos estudantes e não para a formação de meros cientistas.

Ao analisar a finalidade do currículo escolar presente nos dias atuais, percebe-se que muito do discurso escolar na prática ainda é uma reprodução de uma elite dominante e de um sistema capitalista, em que o Estado atua regulando recursos das instituições, promovendo modelos avaliativos e disseminando currículos que constituem práticas pedagógicas oficiais [5,10]. Desse modo, é preciso romper com propostas curriculares técnicas e instrumentais, pois, nessa visão, os interesses populares são reduzidos à dominação social e econômica [10]. E nesse caso, os problemas não se encontram apenas em uma simples mudança de grade curricular. É preciso ir além e, sobretudo, questionar a finalidade da educação, o que envolve toda a comunidade escolar.

O discurso escolar ainda se baseia fortemente nos documentos oficiais. Lopes [3] escreve sobre os Parâmetros Curriculares Nacionais (PCN) e enfatiza que nesses documentos o currículo é desenvolvido em bases construtivistas, em que se busca um ensino mais atrativo e contextualizado. Esses discursos também se voltam para a formação de professores, no intuito de atrelar o processo de formação ao currículo por competências. Segundo a autora, os PCN são as principais referências curriculares para o ensino. Todavia, realiza uma crítica a esses documentos, pois, para ela, uma formação por competências torna-se restrita apenas à sala de aula, ou seja, 
ainda não se faz um currículo que possibilite a inserção e aplicação das questões sociais tendo em vista que só há uma preocupação entre o encontro da formação e do emprego. Outra crítica é com relação à construção de um currículo nacional, como propõe esses documentos, o que impede, de certa forma, o surgimento de princípios regionais. Logo, é importante retirar dos PCN a sua marca de referência padrão, e assim, abrir espaços para novos valores e outros princípios (tomada de iniciativa, autonomia, diálogo, participação social, que fazem parte do conhecido currículo oculto) para o estabelecimento de um currículo de acordo com a realidade escolar.

Silva [5] infere alguns pressupostos que devem guiar a atividade pedagógica, tais como: participação coletiva para construção de currículos, para que sejam elaborados a partir da realidade de cada escola, reorientação constante dos currículos escolares e boa formação de professores afim de se estabelecer relações com a comunidade e desse modo, transformar alguns dos paradigmas atuais já estabelecidos.

Portanto, os debates acerca do currículo remetem também a discussões sobre os conhecimentos importantes para a formação docente, uma vez que os professores são peças fundamentais no processo de ensino-aprendizagem e nos aspectos disseminados por meio dos currículos, principalmente com relação ao papel docente frente a uma educação de qualidade. Therrien e Loiola [11] mencionam que, com o surgimento (a partir do Decreto-presidencial $n^{\circ} 3.276$ de 6 de dezembro de 1999) de uma política voltada para a formação de professores da educação básica e uma ideologia que considera a participação ativa das pessoas para a resolução de problemas corriqueiros, se tem buscado uma reestruturação escolar, com novas orientações e princípios, o que comporta a alternativas e tendências que devem ser inseridas no processo de formação. Puentes e Longarezi [12] também comentam sobre a importância de uma internalização de conhecimentos, a partir de uma relação com a realidade do estudante e os conceitos científicos para que ocorram transformações mentais coletivas e intervenções socioculturais. Nesse enfoque, a didática ocorre a partir da relação entre os três eixos, ensino-aprendizagem-desenvolvimento.

Alguns aspectos sobre o currículo são refletidos neste texto, uma vez que nem todos os alunos vão à escola porque querem estudar e nem todos terão uma formação superior específica [3]. Essa questão conduz à necessidade de outras abordagens, outras propostas, que além de motivadoras, levem em consideração a bagagem cultural e vivência cotidiana dos alunos, pois, na verdade, qualquer currículo já é fruto de uma cultura determinada. Diante disso, surge a busca por propostas de ensino que devem ser incorporadas ao currículo escolar, como por exemplo, as atividades lúdicas e investigativas, abordagens por Ciência/Tecnologia e Sociedade (CTS), entre outras.

Tendo em vista essas abordagens, que podem ser trabalhadas no currículo do ensino de ciências e intensificadas na formação inicial e continuada de professores, nota-se como é integrada a abordagem CTS e sua relação com as discussões históricas, as quais também podem estimular o desenvolvimento de materiais didáticos. Essas abordagens são ainda um desafio para o currículo que está em vigência, entretanto, discussões como essas não podem ser descartadas, pois são consideradas urgentes neste âmbito [4]. O currículo implementado nas escolas ainda se baseia em uma única razão ou preocupação (transmissão de conceitos cientificamente aceitos sem problematização), como se fosse um mapa da verdade e, dessa maneira, acaba por impedir a possibilidade da integralização de múltiplos saberes, pois se reduz a um conhecimento universal e absoluto, geralmente superior aos demais [13].

Num sentido contrário a este currículo hegemônico, defende-se uma abordagem curricular voltada para proporcionar uma construção do conhecimento centrado na formação de estudantes capazes de criticar as mais diversas questões e impasses no âmbito em que o indivíduo está inserido. Sendo assim, deve fazer parte de um currículo questões relacionadas às interações CTS, atreladas a História da Ciência, de modo que tal relação possa contribuir para o desenvolvimento de atitudes e valores, isto é, ter posição crítica diante de problemas sociais.

Os avanços tecnológicos afetam de diversas formas a sociedade, e esta deve se adaptar constantemente as mais variadas informações. Nessa perspectiva, a tomada de consciência é uma atitude que deve ser desenvolvida pelos cidadãos, sendo a escola o principal viés para a construção desses valores. Diante disso, cabe discutir o que muitos trabalhos destacam sobre a inserção do enfoque CTS nos currículos escolares, e que normalmente é ignorado, as relações existentes entre a tecnologia e suas influências externas (aspectos além da atividade científica: 
sociais, políticos, éticos, entre outros). Mesmo assim, a realidade escolar ainda é contrária a essas discussões inter-relacionadas, o processo educativo é organizado de forma linear, e os conceitos descontextualizados [5].

Um currículo CTS foge de atividades pontuais ou da própria abordagem temática uma vez que um currículo bem estruturado desenvolve atividades que permite a integralização dos saberes e dessa forma, pode ser discutido de diversas formas, nesse caso, a epistemologia conceitual deve ser considerada, ou seja, as discussões sócio-históricas. Isso significa dizer que o ensino de ciências pode ser interdisciplinar, pois possui relação entre áreas da ciência, da psicologia, da história e filosofia das ciências [14]. O movimento CTS destaca que se deve formar pessoas que sejam praticantes de atividades democráticas, que contribuam para uma sociedade mais reflexiva e uma leitura do mundo [15].

Ainda nesta ideia curricular, Cachapuz, Praia e Jorge [16] enfatizam três dimensões que podem proporcionar essa ligação entre os conceitos e os valores que são promovidos em um currículo com o enfoque CTS. Os autores apresentam as três dimensões ocorrendo simultaneamente, que são:

[...] aprender Ciência (aquisição e desenvolvimento de conhecimento conceitual); aprender sobre Ciência (compreensão da natureza e métodos da Ciência, evolução e história do seu desenvolvimento bem como uma atitude de abertura e interesse pelas relações complexas entre Ciência, Tecnologia, Sociedade e Ambiente); aprender a fazer Ciência (competências para desenvolver percursos de pesquisa e resolução de problemas) (CACHAPUZ; PRAIA; JORGE; 2004, p. 367).

$\mathrm{Na}$ busca de uma aproximação entre o ensino de ciências e investigação científica, considerando as relações CTS a partir de um processo de mediação do professor, defende-se a necessidade de inclusão das discussões sobre História da Ciência para a formação inicial de professores, com a finalidade de diminuir algumas incoerências no âmbito do ensino. É importante não somente inserir discussões epistemológicas nos currículos escolares e nos cursos superiores, mas também criar oportunidades para que esses debates ocorram durante a formação continuada de professores, pois ensinar utilizando uma metodologia que não esteve presente em sua formação, geralmente, é uma tarefa difícil para os docentes da educação básica.

Tendo em vista a importância da História da Ciência para o ensino e uma perspectiva social da ciência, a qual pode ser incorporada ao currículo CTS, vários autores discutem a respeito dessa tendência que pode levar uma melhor compreensão da matéria que é ensinada pelos professores [17].

No âmbito do Ensino de Ciências, há uma necessidade de que no currículo das escolas da educação básica sejam inclusas as implicações sociais e culturais, que de alguma forma relacionam-se com o conhecimento cientifico. Nesse contexto, para Martins [18], é de grande importância que se problematize, considerando-se determinado período histórico, como surgiram as teorias científicas, de que maneira os cientistas trabalhavam, quais ideias eram aceitas e quais não eram, e ainda as que prevaleceram atualmente. Objetivando-se um desenvolvimento integral dos estudantes da educação básica, com base em uma visão mais "elaborada" da ciência, em que, o pensamento científico é construído pela prática social, torna-se relevante papel essas discussões no ensino [12]. Pois, com base nas tendências (CTS/HC), o ensino deve ser fundamentado em interações humanas voltadas para seres humanos e, portanto, influenciado pelas inter-relações indivíduo-sociedade. Estudos desenvolvidos por Chinelli Ferreira e Aguiar [17] e Martins [18] defendem uma inclusão de discussões sobre com esse tipo de abordagem nas instituições e cursos formadores de professores, uma vez que há ainda, a ausência de discussões históricas nos currículos, resistindo à ideia linear e cumulativa dos conceitos científicos.

Tratando-se dos conhecimentos escolares, os quais também fazem parte da definição de currículo, destaca-se um cenário pedagógico em que há poucas discussões históricas presentes nas teorizações dos conceitos curriculares, muitas vezes apresentadas em pequenos recortes, fora da 
discussão conceitual que esteja sendo realizada. Costuma-se apresentar apenas os cientistas que "deram certo", deixando de lado as controvérsias científicas que ocorreram ao longo da história $[19,20]$. Puentes e Longarezi [12] mencionam que essa maneira como o conhecimento é apresentado faz com que os estudantes da educação básica se apropriem de conceitos prontos e acabados e desenvolvam concepções abstratas e acríticas. De acordo com os autores, a apropriação do conhecimento é uma construção humana e envolve o estabelecimento de novas aptidões psíquicas e uma boa base conceitual.

Em uma pesquisa realizada por Chinelli, Ferreira e Aguiar [17], os autores observaram que apesar da relevância das discussões sócio históricas para o processo de formação de professores e aprendizagem dos alunos, a maioria dos docentes ainda se encontram imersos em uma crise paradigmática, a qual pode aprimorar os problemas de aprendizagem dos alunos. Logo, há um conflito entre um currículo que privilegia uma visão de ciência a partir dos aspectos sociais humanizados e suas relações CTS, versus um currículo prático que enfatiza uma ciência pura, absoluta e descontextualizada. Dessa forma, pode-se inferir que, apesar da defesa para inclusão da primeira vertente no âmbito educacional, percebe-se não ser simples modificar, a princípio, as concepções dos docentes e também a estrutura curricular da escola, logo de imediato, por isso surge o desafio de intensificar discussões e atividades pautadas nas relações entre a abordagem CTS/HC já durante a formação inicial de professores.

Ainda assim, a escola numa perspectiva epistemológica é permeada por intencionalidades e paradigmas. E cabe a essa instituição sistematizar o conhecimento dos alunos, de maneira que eles consigam solucionar problemas reais e que necessitem de informações científicas. A Figura 1 sintetiza a finalidade de um currículo crítico de ensino, baseado em ciência/tecnologia e sociedade e suas relações com os aspectos históricos do conhecimento científico em contraposição ao currículo organizado de maneira tradicional, caracterizado por conteúdos sequenciais e estáticos.

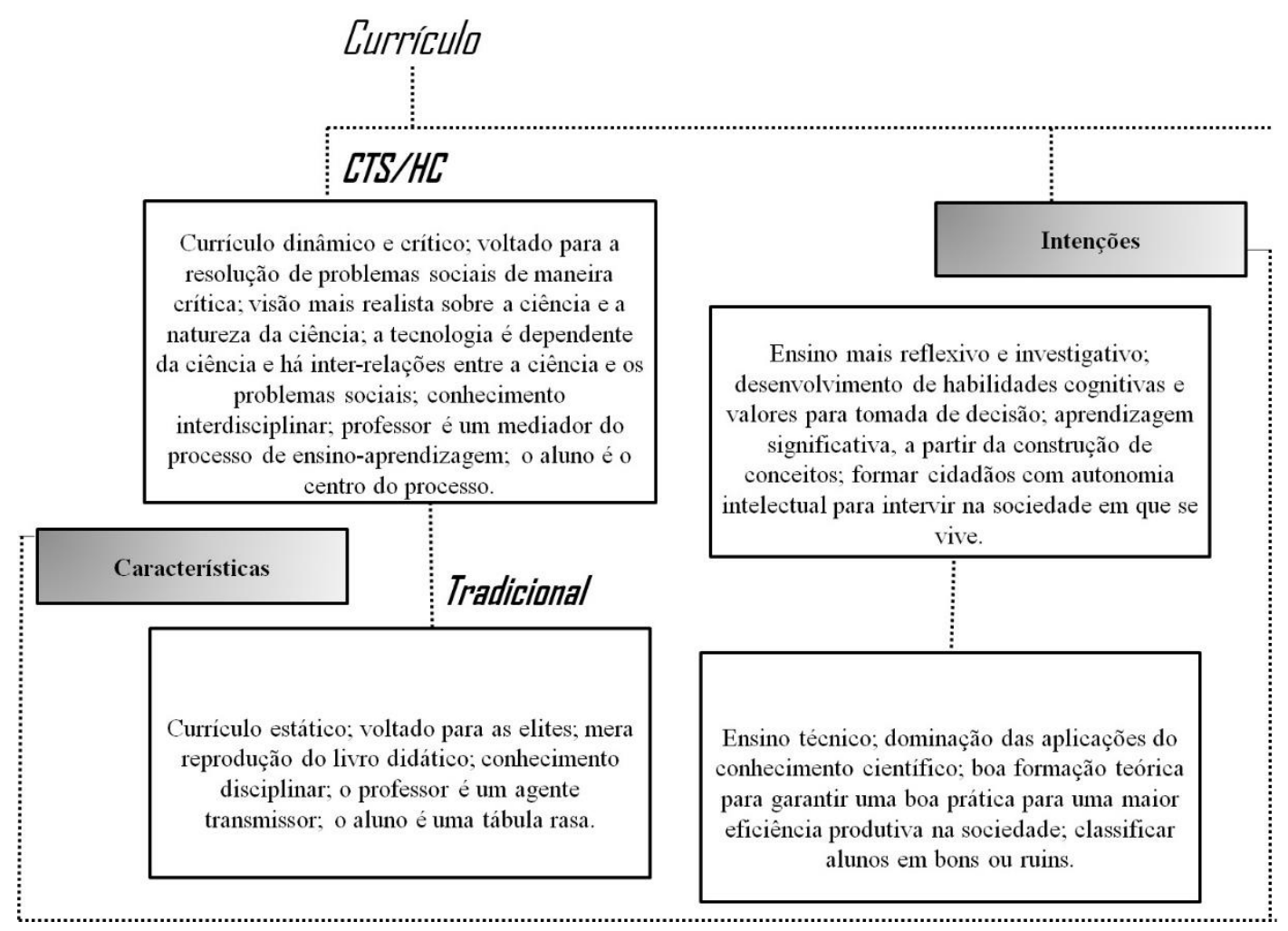

Figura 1 - Descrição das relações do ensino CTS/HC em contraste com um currículo tradicional.

Fonte: Arquivo dos autores, 2015. 
Percebe-se em uma análise da Figura 1 que um currículo com enfoque nas tendências CTS e HC está voltado para a formação de alunos críticos e ativos e que sejam atuantes em seu meio social. O currículo com base nesses princípios tem como finalidade a tomada de decisão, interação entre professor e aluno e também uma compreensão mais realista sobre a natureza da ciência para ensinar e aprender sobre ciência, em que a ciência se torna uma construção humana, a qual recebe influência de fatores externos, como as questões sociais, políticas e econômicas [23]. Nesse caso, o currículo não é apenas restrito à escola e nem deve ser hegemônico, diante de uma grande diversidade cultural. Deve partir de questões locais, levando em consideração as particularidades de cada região e as vivências dos alunos. Um currículo crítico ultrapassa o simples jogo de ler palavras e fórmulas; baseia-se em um ensino contextualizado com perspectivas construtivistas do ponto de vista social [15]. Contudo, a busca por um ensino mais investigativo e reflexivo necessita da participação do professor que deve ser um mediador do processo de ensino-aprendizagem, e não um mero transmissor dos discursos presentes nos livros didáticos. O aluno, por sua vez, encontra-se no centro de qualquer atividade [7]. As avaliações presentes nesse currículo devem ser processuais e não classificatórias, ou seja, o objetivo não é classificar alunos bons ou ruins através do seu desempenho em provas escolares, mas formar o aluno para que possa intervir em seu meio [21, 7]. Sendo assim, o modelo transmissão-recepção ou a conhecida educação bancária discutida por Paulo Freire não se encaixa nesse currículo [22].

Apesar dos inúmeros benefícios de um currículo crítico com base CTS/HC, bastante contrário ao tradicional, é importante perceber que todas as vantagens também devem estar pautadas em uma formação de professores sólida, em que sejam apresentadas e debatidas as diversas questões que permeiam o currículo escolar para que assim, o professor se torne um educador agente do conhecimento e não um detentor de conceitos.

Por tudo que foi apresentado, o currículo crítico possibilita discussões de problemas reais, em que a ciência é utilizada para compreender e explicar determinados fenômenos, sendo influenciada pelos meios filosóficos, psicológicos, culturais, sociais e científicos [23]. O currículo CTS abrange esse contexto, pois é um currículo que permite contribuições interdisciplinares, um destaque disso, é a inserção da História da Ciência que auxilia a compreensão dos fatores que contribuíram para as descobertas ao longo do tempo, bem como a construção da ciência estudada de forma contextual, fornecendo assim, uma visão ampla da ciência, por construir debates pautados em distintos olhares, diferentemente do currículo tradicional.

\section{CONCLUSÃO}

As discussões levantadas neste estudo permitem realizar algumas considerações. Uma breve análise já evidencia que o currículo escolar é fortemente político, no sentido de atuar como um ato ideológico e também emancipatório (dimensão política, que pode ir além da alienação), e permeado por interesses de classes, mas que deve ir além dos interesses impostos pelo sistema produtivo e econômico, o qual busca um simples eficienticismo social. Contudo, as questões escolares não devem apenas restringir-se aos interesses capitalistas do mundo produtivo, sendo necessário uma re(construção) das hierarquias já estabelecidas no ensino vigente, tais como as discussões que colocam no bojo a dimensão de um currículo crítico, elaborado por meio de problemas reais e uma dimensão social (um currículo em bases CTS permite isso). Desse modo, tanto os currículos, quanto os métodos avaliativos e a prática precisam ser redefinidos.

O currículo deve ser constituído por propostas inter-relacionadas, traduzidas por saberes e significados que estejam aptos para serem ensinados. As políticas curriculares, por sua vez, envolvem o processo de planejamento e as esferas sociais e devem ir além do poder central, superando as concepções tecnicistas que integram o currículo tradicional e que não permitem questionar o que é ensinado na escola. Assim, pode-se inferir sobre a importância de abordagens pedagógicas como o enfoque CTS sob o prisma da História da Ciência a fim de compor um currículo crítico, direcionado para a formação de alunos ativos. O desenvolvimento dessas atividades permite argumentar acerca da possibilidade do uso dessas tendências (abordagens CTS/HC) frente ao ensino desfragmentado e disciplinar, bem como contribuir para estruturar um currículo mais amplo para a sociedade, no sentido de inserir tais discussões, de maneira atrelada 
as necessidades sociais de cada região. Todavia, é fundamental que essas discussões, em alternativa ao currículo tradicional, façam parte do âmbito da formação de professores, principalmente do processo de formação inicial, no intuito de que, assim, os futuros docentes desenvolvam um pensamento mais crítico e uma melhor compreensão dos conteúdos científicos atrelados aos seus processos históricos de elaboração e, sobretudo, levem esses debates para os futuros alunos, de forma que o currículo vigente comece a caminhar para uma abordagem crítica. Entende-se que este não é um processo rápido e simples, que requer mudanças de estruturas curriculares e não apenas nos currículos escolares, mas também, na postura dos professores. Por isso, é imprescindível intensificar essas discussões no âmbito do ensino de ciências, já durante os cursos de formação de professores, para que assim, sejam incorporados, mesmo que aos poucos, ao cotidiano escolar.

\section{REFERÊNCIAS BIBLIOGRÁFICAS}

1. Moreira AF, Candau VM. Indagações sobre currículo: currículo, conhecimento e cultura. Brasília: Ministério da Educação; Secretaria de Educação Básica, 2006.

2. Fávero LL. Coesão e coerência textuais. São Paulo: Ática, 1991.

3. Lopes AC. Políticas curriculares: continuidade ou mudança de rumos? Revista Brasileira de Educação, (26), 2004. p. 109-83.

4. Lopes ARC, Macedo E. (Org.). Políticas de currículo em múltiplos contextos. São Paulo: Cortez, 2006, $272 \mathrm{p}$.

5. Silva AFG. A Construção do currículo na perspectiva popular crítica: das falas significativas as práticas contextualizadas. 2004. 405 f. Tese (Doutorado em Educação)-Pontifícia Universidade Católica de São Paulo, São Paulo, 2004.

6. Gouw AMS, Mota HS, Bizzo N. O currículo de ciências e o interesse dos estudantes brasileiros: uma aproximação necessária. Cadernos Cenpec, São Paulo, 3(2), 2003. p. 7-34.

7. Veiga IPA. Ensinar: uma atividade complexa e laboriosa. In: Veiga IPA. (Org.). Lições de didática. Campinas: Papirus, 2007. p. 13-33.

8. Moreira AFB. Conhecimento, currículo e ensino: questões e perspectivas. Em Aberto, Brasília, 12(58), 1993. p. 45-53.

9. Chassot A. Alfabetização científica: questões e desafios para a educação. 4. ed. Ijuí: Unijuí, 2006. 440 p.

10. Lopes ARC. Políticas de integração curricular. Rio de Janeiro: EdUERJ, 2008. 184 p.

11. Therrien J, Loiola FA. Experiência e competência no ensino: pistas e reflexões sobre a natureza do saber-ensinar na perspectiva da ergonomia do trabalho docente. Educação e Sociedade, Campinas, 22(74), 2001, p. 143-60.

12. Puentes, RV, Longarezi, AM. Escola e didática desenvolvimental: seu campo conceitual na tradição da teoria histórico-cultural. Educação em Revista, Belo Horizonte, 29, 2013, p. 247-71.

13. Lopes ARC. Conhecimento escolar: ciência e cotidiano. Rio de Janeiro: EdUERJ, 1999. 236 p.

14. Cachapuz A, Paixão F, Lopes JB, Guerra, CD. O Estado da arte da pesquisa em educação em ciências: linhas de pesquisa e o caso "Ciência-tecnologia-sociedade". ALEXANDRIA Revista de Educação em Ciência e Tecnologia, 1(1), 2008. p. 27-49.

15. Auler D. Alfabetização Científico-tecnológica: um novo "paradigma"? ENSAIO - Pesquisa em Educação em Ciências, Blumenau, 5(1), 2003. p. 1-16.

16. Cachapuz A, Praia J, Jorge M. Da educação em Ciência às orientações para o ensino das ciências: Um repensar epistemológico. Ciência \& Educação, 10(3), 2004. p. 363-81.

17. Chinelli, MV, Ferreira MVS, Aguiar LEV. Epistemologia em sala de aula: a natureza da ciência e da atividade científica na prática profissional de professores de ciências. Ciência e Educação, 16(1), 2010. p. 17-35.

18. Martins, RA. A História das ciências e seus usos na educação. In: Silva CC. (Org.). História e filosofia das ciências. São Paulo: Ed. Livraria da Física, 2006. p. XXI-XXXIV.

19. Peduzzi L. O. Sobre a utilização didática da História da Ciência. In: PIETROCOLA, M. Ensino de física: conteúdo, metodologia e epistemologia numa concepção integradora. Florianópolis: Editora da UFSC, 2001, p. 151-70.

20.Batista RP. História da ciência: investigação do tema em livros didáticos do ensino fundamental. Florianópolis: UFSC, 2002.

21. Carvalho AMP, Gil-Pérez, D. Formação de professores de ciências: tendências e inovações. 3nd ed. Trad.: Sandra Valenzuela. São Paulo: Cortez, 1998.

22. Freire. Pedagogia do oprimido. Rio de Janeiro: Paz e Terra, 1987. 